\title{
Distinguishing and de ning the role of a technical leader in outsourced teams developing IT solutions using Scrum
}

\author{
Jan Werewka \\ Department of Applied Com- \\ puter Science \\ AGH University of Science and \\ Technology \\ al. Mickiewicza 30, 30-059 \\ Kraków, Poland \\ Email: werewka@agh.edu.pl
}

\author{
Marcelina Wietecha \\ Faculty of Management \\ AGH University of Science and \\ Technology \\ al. Mickiewicza 30, 30-059 \\ Kraków, Poland \\ Email:marcelina.wietecha@gmail. \\ com
}

\author{
Kamil Wołczyk \\ Department of Applied Com- \\ puter Science \\ AGH University of Science and \\ Technology \\ al. Mickiewicza 30, 30-059 \\ Kraków, Poland
}

\begin{abstract}
Outsourcing software development is gaining popularity and importance. The value of an outsourced team is much higher when this team can be represented by a technical leader. Many outsourced teams use various agile methodologies, Scrum being the most popular among them. Distinguishing specialized roles in teams, such as e.g. a role of a technical leader, does not conform to some agile principles. When building an IT system, it is important for the team to have a technical leader who can communicate with internal and external stakeholders. In this paper the aspects of the communication abilities of a technical leader are considered in more detail based on conducted surveys. Developing successful technical leadership is not an easy task for a company, and that is why career paths of software engineers are an important issue regarding HR competencies and leveraging costs. The paper offers some remarks concerning useful competences of technical leaders based on an example related to databases.
\end{abstract}

\section{INTRODUCTION}

$\mathrm{I}$ $\mathrm{N}$ IT companies many employees are software developers. An important issue for businesses and the whole IT market is their proper competence development. Nowadays, many development teams work using agile methodologies, out of which Scrum is the most popular. Having a technical leader in a team can significantly increase the value of the team, e.g. when the team is outsourced. According to Scrum principles, specialization of team members is not a desirable feature. However, outsourced teams can greatly benefit from defining the role of a leader who will perform certain functions. If teams are not outsourced, sometimes it is better to have a separate company division dealing with technical leadership.

Our hypothesis states that it is advantageous to create the role of a technical leader in Scrum teams because it results in increased efficiency and quality. It is also possible to define the requirements for a technical leader and his role in the team. On the other hand, building proper leadership in teams is a long-lasting and costly process.

The problem is that Scrum defines a team as a group of collaborators that consists of people with assigned roles: a Scrum master, a product owner, and a team member (developer). The team is inherently self-organized and no one outside the group should affect their work. Developers are responsible for creating a product. All team members contribute to product development, therefore, they are not only programmers, but also testers, analysts, etc.. In [1] some informal, implicit, transient, and spontaneous roles are identified in self-organizing teams. The selected roles of a Mentor, Coordinator, Translator, Champion, Promoter, and Terminator help the team to become more efficient. In our study we investigate the role of a technical leader in a broader context of IT company needs.

To have a basis for proposed solutions, a series of surveys were conducted in Kraków, Poland. There are many software development outsourcing projects in this region, which is the biggest outsourcing center in Europe (it occupies the ninth place in the world, according to Tholons [2]). Outsourcing causes a division of teams into these which work in the office (on-site), and these which work remotely (offshore). The issue of outsourcing IT teams has been addressed in various publications.

However, few papers have investigated applying agile methodologies and outsourcing solutions in distributed software development. In [3] adapting the Scrum methodology to work in Network Organization is proposed. The Scrum core roles are extended, and changes in Scrum artifacts are proposed; changes and high competition being the cornerstone of the approach. In [4] the problem of an effective use of Scrum practices in Global Software Development is investigated. The paper reports a multi-case study that investigates the impact of key contextual project factors on the use of Scrum practices in GSD. A similar study [5] proposes a SO-SPRM (Software Outsourcing Service Provider Relationship Model) model concerning the cooperation of both teams in the customer's office and remote teams. The study, which was carried out in India, reveals that for global software development (GSD) projects, it is important to share knowledge, trust, commitment, and flow requirements. In turn, a study conducted in Sri Lanka [6] deals with the issue of verification of software quality by outsourced companies. 
In our study, we consider four aspects of technical leadership:

1. Technical leadership in autonomous Scrum teams. In this case teams that manage projects are associated with customers, and teams developing software are part of IT companies. Software development teams should be able to make their own technical decisions, so the role of a technical leader is important. It is necessary to identify competencies of technical leadership crucial for team members. Therefore, we decided to conduct surveys to determine team members' views on this role.

2. HR (Human Resources) management in an IT company which takes into consideration a technical leadership position. In this case it is important to develop skills corresponding to company's needs. This can be obtained by defining career paths and talent management to ensure retention of valuable staff members.

3. Software developers try to develop their own careers. It would be interesting to have knowledge regarding the orientation of their development in the context of the company. Usually they tend to choose a technology or management path. The survey conducted by the authors should show the developers' perception of the roles of a technical leader and a project manager.

4. Technical leadership requirement defined by IT companies depends on current needs. A good way to identify technical leadership requirements is to investigate companies' job offers. In the paper job offers investigated are limited to technical leadership in the data base domain.

Considering all four above mentioned aspects offers a full picture of the role of technical leadership in an IT company. On the basis of such information, sustainable development of human resources can be proposed.

\section{TECHNICAL LEADER ALLOCATION IN SOFTWARE DEVELOPMENT COMPANIES}

The quality of IT systems developed by a company depends on management of software development and the competency and availability of experts. Experts can specialize in various areas, e.g. connected to the domain, technology, or architecture. They can be in top management, in a specialized company division, or allocated to teams. Putting experts in a specialized division may cause bottlenecks and a lack of deep expert knowledge of the IT systems under development. Experts can be assigned to each team, but this can lead to a lack of specialists in the company. Assigning technical experts to the team is favorable for outsourced teams.

The problem to be solved is connected with how to best allocate experts and what type of competencies are needed. The allocation of technical experts depends on many factors. In case of an IT company that intends to outsource whole teams, having technical experts inside the teams is essential.
In a software development company, technical experts may be found in top management, in specialized divisions, or in teams. Fig. 1 shows possible allocations of technical experts with relation to software development and operation of companies.

Placing technical experts in top-level management can positively influence the outcome of an IT company. The study [7] examines how the inclusion of a technology leader (e.g., CIO or CTO) in the top-level management team influences the company's performance.

Experts can be gathered in a specialized division to support institutional solutions. TOGAF (The Open Group Architecture Framework) provides [8] a method of designing enterprise architectures. In TOGAF, the Architecture Board is a key element of architecture governance strategy. This body represents all key stakeholders in architecture. In project management solutions such as e.g. PMBOK [9], a PMO (Project Management Office) is proposed for leading and supporting projects. In the process of adapting enterprise architecture in a software development company [10], it is important to define the architect's role in software project implementation. Enterprise architects should be responsible for the coordination of work among units and the overall implementation of the company's strategy.

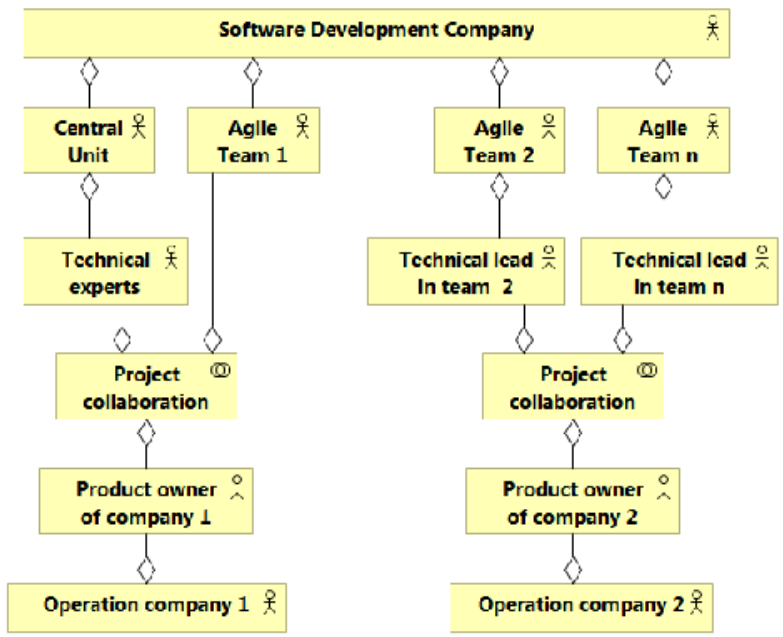

Fig. 1 Possible roles of a technical leader in software development collaboration

Placing experts in a team is important, as shown by the following case study. A solution architect is assigned to each project and is responsible for preparing and supervising the implementation of the entire solution architecture. Solution architects should cooperate closely with project managers and other persons responsible for collecting client's business requirements so that the developed solution best suits the client's needs. It is assumed [10] that a solution architect is not an active member of a project group. This solution proved to be incorrect because it leads to situations in which solution architecture is developed independently of implementation, and this might result in inconsistencies between them. 


\section{THE ROLE OF A TECHNICAL LEADER IN SOFTWARE DEVELOPMENT TEAMS}

There are many different definitions of leadership and leader in the literature. Leadership is defined here following [11] as the process of influencing others towards achieving some kind of a desired outcome. A leader is the owner of the process. A technical leader is a person who combines technical and soft skills in managing a group of people. This helps the project or the manager-especially if the manager does not have adequate technical knowledge - to lead the project to success.

A technical leader in a development team is a person who leads the team and acts as a guide for others thanks to his broad technical knowledge. He is an expert at technical issues, which allows him to organize and support team members in the implementation of tasks and resolve disputes in the team. He is the team representative and helps the team to overcome technical impediments and external stakeholders to understand technical issues.

There are other names used for a technical leader, such as a technical lead, a tech lead, and a tech leader. These names are considered synonymous. The term 'technical leader' seems more formal than 'technical lead'.

It is very important to choose the right person for the technical leader position. A technical leader must have above-average technical knowledge, engender respect and trust between team members, and be accepted by the team. The role is always played by a team member who is primarily a developer. There are various ways to identify this person. Most commonly, the leader is selected naturally in the team as the person with the broadest technical knowledge who has authority in technical issues. A team that chooses its own leader independently will never have a problem with accepting the role. It is very common that the person with the most experience is imposed on the team from outside as a leader. In selecting a leader, both hard and soft competences should be considered. A company can also ensure proper preparation of the candidate through training.

The technical leader role may cover different functions, e.g.:

1) Developing team building. The role and tasks of a leader are focused on team building. A team is defined [12] as "a small number of people with complementary skills who are committed to a common purpose, performance goals, and an approach for which they hold themselves mutually accountable".

2) Team learning. A technical leader plays an important role in the process of team learning. Clutterbuck says [13] that this process is cyclical and consists of five steps: (1) Determining development goals of the team; (2) Management of the learning process; (3) Learning process evaluation; (4) Knowledge sharing; (5) Determining relationship between effort put into the learning and understanding of the process.

3) Motivating the team. Motivating the team needs concrete actions that lead to the achievement of a predetermined purpose. Motivation is the result of unmet needs and occurs when a person becomes aware of the final outcome of his actions. In other words, need motivates action, which leads to achieving the goal [14]. A technical leader who wants motivation to be effective has to clearly define team goals. The role of a technical leader in motivating a team primarily consists of encouraging and supporting team members, giving feedback, and indicating the direction towards the goal. A leader should reward the team by offering his recognition and praise, entrusting greater responsibility, and showing trust by allowing more freedom in decision-making. The inner motivation of each member is also very important. It is created by ambition, responsibility, satisfaction, desire to develop, and the interests of each particular person. A technical leader should recognize the potential of each individual and best use it for the success of the whole team [14].

4) Communication with stakeholders. One of the major tasks of a technical leader is communication with the stakeholders on behalf of the team. He is the link between the developers and the outside world, for which technical issues are difficult to understand. A leader, who is, first of all, a developer, must have the ability to translate technical language for stakeholders [15]. He helps developers to understand and clarify the requirements of the customer. In [16].

The technical leader role should be beneficial for the software development company. A technical leader with inadequate technical and soft competences may result in the inefficient work of the team.

\section{COMPETENCY OF A TECHNICAL LEADER IN A SCRUM TEAM}

Scrum is the most popular agile software development methodology. According to the Scrum Guide [17], a Scrum team consists of a product owner, a scrum master, and the development team. The team is responsible for delivering the technical solution, which usually consists of working software. The team members are developers with different competencies, knowledge and experience. The team can include programmers, testers, analysts and solution architects. The proposed size of the team is $7 \pm 2$ members only, as this retains the ability to communicate and share knowledge.

The fact is that a technical leader in Scrum never appears as a formal role, but Rob Friesel [15] argues that the creation of a Scrum Tech Lead brings many benefits if it serves the leadership. In [16], a similar approach is presented which states that every Scrum team needs a Technical Lead to bridge the gap between technical perspectives. The author also emphasizes that responsibility for the code, making decisions autonomously, and imposing his opinions are not the Tech Lead's duties. According to [15], the Scrum Tech Lead's responsibilities fall into three categories: technical leadership, mentoring and support, and technical communication.

In order to distinguish the roles of a technical leader in Scrum teams, several surveys were conducted among 
employees of various teams in IT companies with the goal of gaining insight into these issues. Their primary objective was to obtain opinions on the desired characteristics of a technical leader, while the secondary theme was to find out how a technical team leader functions in real IT companies. In the first case, it was important to get important information about the respondents. Because only 25 people were interviewed, they were asked about the total number of years they had worked in IT teams and about the number of teams in which they had worked. The results are shown in Fig. 2.

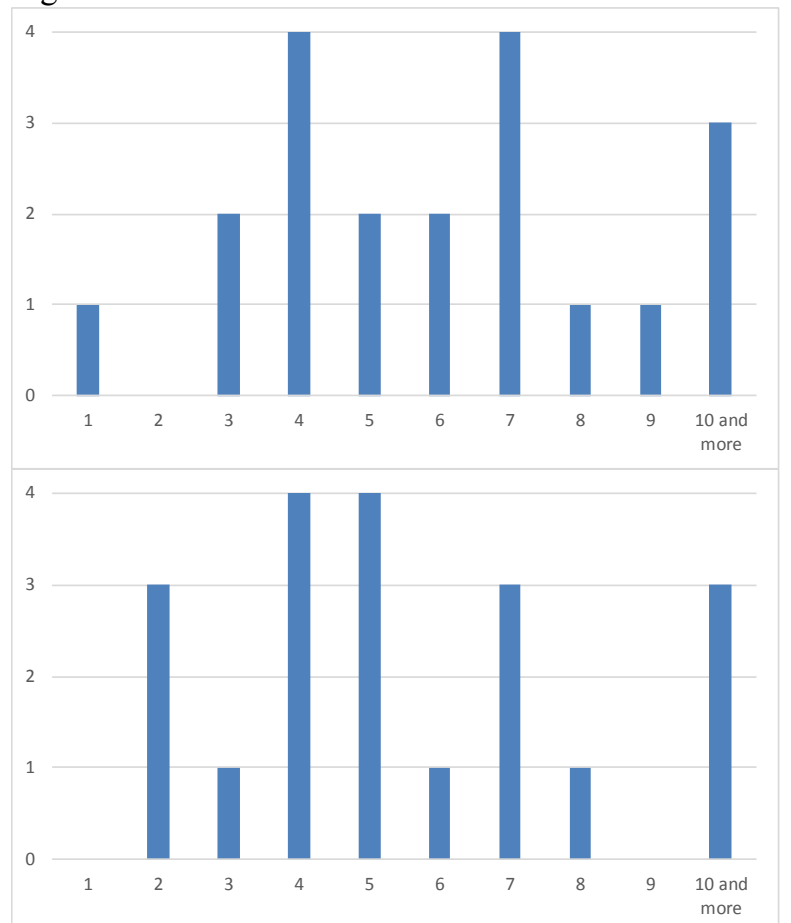

Fig. 2 Respondents' characteristics: years of work and the number of teams in which they have worked
The next question was connected with the presence of a leader in teams in which the respondents had worked. 80\% of respondents answered this question positively. The second question clarified whether technical leaders were present in product development based on Scrum. In this case, $75 \%$ of respondents answered positively. From the above results, it is clear that having a technical leader is quite common in software teams.

The aim of the next question was to rank desirable features of a technical leader based on a group of 10 preselected features. The group of features was based on [18] and included: extensive knowledge and experience; communication ability; negotiation and mediation ability; building sustainable relationships in a team; openness to change; assertiveness; perseverance and patience in goal reaching; self-confidence; courage in taking decisions and responsibility; calmness.

For each characteristic respondents attributed a weight in the range 1-10. A weight of 1 meant the least important characteristic, and a weight of 10 meant the most desirable characteristic of a leader. The last column denoted as $\sum$ in Tab. 1 gives a total number of points collected for each characteristic. The obtained results reveal three characteristics - ability to communicate, extensive knowledge and experience, and the courage to make decisions - as the most important ones.

Another question was a supplementary list of other features of a technical leader that positively affect teamwork which were not included in the preselected group of 10 features. According to the respondents, who were specialists from the IT industry, a technical leader should also display good organization of work, charisma, honesty, reliability, knowledge transfer ability, vigor, understanding, positive attitude, ability to listen, and involvement.

TABLE I. MOST IMPORTANT CHARACTERISTICS OF TEAM LEADER AS SEEN FROM THE TEAM MEMBER'S PERSPRECTIVE

\begin{tabular}{|l|c|c|c|c|c|c|c|c|c|c|c|}
\hline & 1 & 2 & 3 & 4 & 5 & 6 & 7 & 8 & 9 & 10 & $\Sigma$ \\
\hline Communication ability & 0 & 0 & 0 & 0 & 0 & 0 & 0 & 24 & 63 & 100 & $\mathbf{1 8 7}$ \\
\hline Extensive knowledge and experience & 0 & 0 & 0 & 0 & 0 & 6 & 28 & 32 & 18 & 90 & $\mathbf{1 7 4}$ \\
\hline Courage in taking decisions and responsibility & 0 & 4 & 0 & 4 & 5 & 6 & 0 & 8 & 63 & 70 & $\mathbf{1 6 0}$ \\
\hline Assertiveness & 0 & 0 & 3 & 8 & 20 & 6 & 14 & 16 & 45 & 30 & $\mathbf{1 4 2}$ \\
\hline Openness to change & 0 & 2 & 0 & 8 & 0 & 24 & 35 & 8 & 54 & 10 & $\mathbf{1 4 1}$ \\
\hline Negotiation and mediation ability & 1 & 2 & 6 & 0 & 5 & 12 & 14 & 40 & 9 & 50 & $\mathbf{1 3 9}$ \\
\hline Self confidence & 0 & 0 & 12 & 0 & 10 & 6 & 28 & 40 & 9 & 30 & $\mathbf{1 3 5}$ \\
\hline Perseverance and patience in achieving goals & 2 & 0 & 0 & 12 & 0 & 12 & 21 & 48 & 9 & 30 & $\mathbf{1 3 4}$ \\
\hline Sustainable building of relationships in a team & 0 & 2 & 9 & 0 & 15 & 18 & 28 & 8 & 9 & 40 & $\mathbf{1 2 9}$ \\
\hline Calmness & 6 & 4 & 0 & 8 & 0 & 6 & 7 & 32 & 18 & 20 & $\mathbf{1 0 1}$ \\
\hline
\end{tabular}

Teams expect a leader to possess a certain level of soft competencies, e.g. the ability to transfer knowledge or listen, as well as appropriate character traits such as vigor, understanding, or a positive attitude. These qualities break down barriers between team members and a leader, making co-workers feel at ease. Commitment is also important for team members, as is reliability and good organizational skills, as these provide a role model for others to follow. 


\section{V.THE TECHNICAL LEADER'S CAREER PATH AND COMPETENCY DEVELOPMENT}

Generally, competency of a technical leader can be divided into domain and non-domain areas. Domain aspects are related to software engineering, while the non-domain aspects considered here mainly refer to social and management skills.

Basic domain requirements placed on a technical leader revolve around education and work experience. Technical leaders are required to possess skills related to programming language standards, encoding methods, company coding standards, and quality requirements. A software engineering competency model (SWECOM) may be used as a reference. This describes [19] competencies for software engineers. Additionally, it is also necessary to have knowledge of innovative solutions in related areas

The non-domain characteristics of a technical leader cover appropriate predispositions and soft skills. By analyzing published job offers listing soft skills that IT companies require of software developers and project managers, the study [20] examines the issues of employees' competency definitions and career building in IT companies. In the conclusions, some proposals for HR departments and developers are given regarding the transition from software developer to project management positions. In [21], a study is conducted to find appropriate communication practices to be used in global outsourced agile software development projects.

For most IT companies defining a technical leader role for Scrum teams is followed by defining a technical leader position in the structure of the organization. After investigating career paths solutions in different IT companies, a typical example of career paths of technical leaders used in some IT companies is given in Fig. 3. Career paths depend largely on the size of the company, the level of the employees' technical knowledge, relationships with customers, and the type of products developed. Employees often play multiple roles in small companies. A classic path to leadership begins with a Junior Developer and then, when the employee is more independent, he is promoted to the position of a Developer. After gaining adequate experience, he becomes a Senior Developer. He then participates in the creation of products and supports less experienced team members, shares knowledge, and supervises work. Over time, a Senior Developer may decide to take on an additional role such as a Team Leader, which often necessitates the acquisition of extra soft skills. This process often requires the involvement of other people, for example, a special personal trainer. A Senior Developer can also remain in this position and become a Technical Leader. Companies frequently nominate unsuitable developers who do not have essential soft skills or competences needed for proper communication and human resources management.

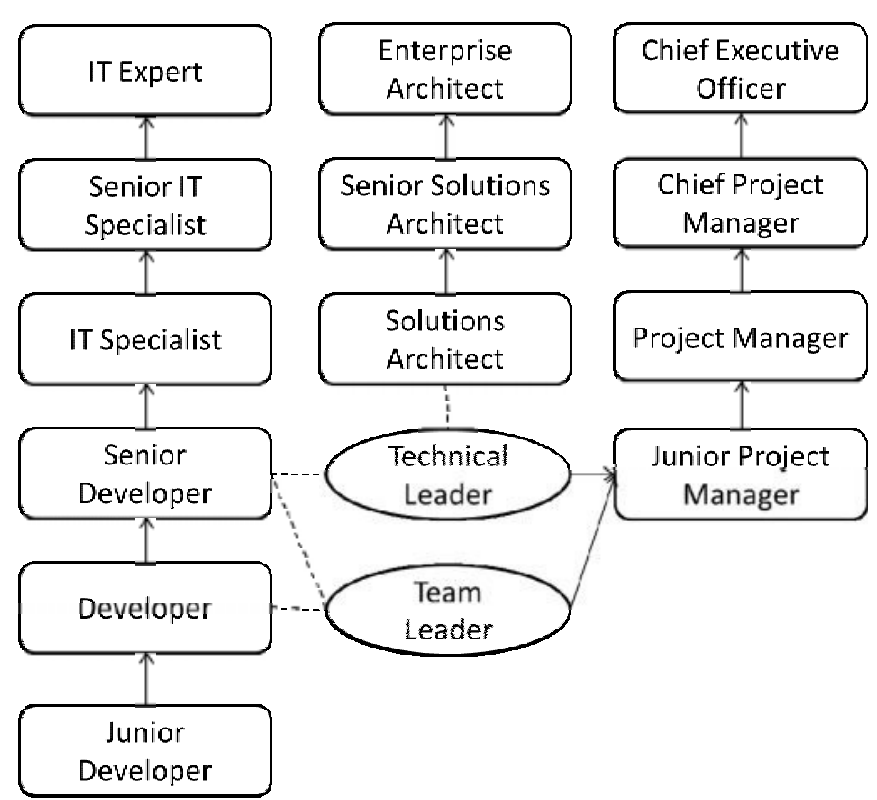

Fig. 3 Software engineer career paths, including a technical leader role

The role of a Technical Leader is usually offered to the person with the longest professional experience and the most technical knowledge, and little or no attention is paid to his soft skills. As shown in Fig. 3, fulfilling additional roles gives the developer the opportunity to an easier transition to being a Solution Architect or retraining as a Project Manager. Being a Solution Architect requires more technical competences than can be acquired as a Developer. A Project Manager takes a completely different career path that involves retraining. It is worth considering to what extent the competences an employee acquires as a Technical Leader overlap with the competences of a Project Manager. This raises the question whether being a Technical Leader is a good starting point for a career in project management.

Becoming a team leader may be an important step on the way to a project management position. Two surveys were conducted to compare the competences of technical leaders (Q1) and project managers (Q2). The results of the first survey are described in chapter 4 . Survey Q1 was conducted among software developers in various IT companies in order to assess the importance of project manager's soft skills from the point of view of developers. Survey Q2 was distributed in September 2015 to a group of selected 31 persons as a Google form.

As is evident from the surveys, project managers are expected to be able to manage themselves and their work, communicate with and understand other people, and negotiate. According to Q2 respondents, communication skills are the most important for this role. Negotiation skills also are useful in technical leadership, but to a lesser extent. Developers, however, say that one of the most important competencies of a technical leader is extensive knowledge and experience. In survey Q2 his most crucial skills include the ability to communicate his knowledge, the desire to share it with others, and a desire to be up to date with technical 
innovations; these skills appear at lower positions on the list of Project Manager competencies.

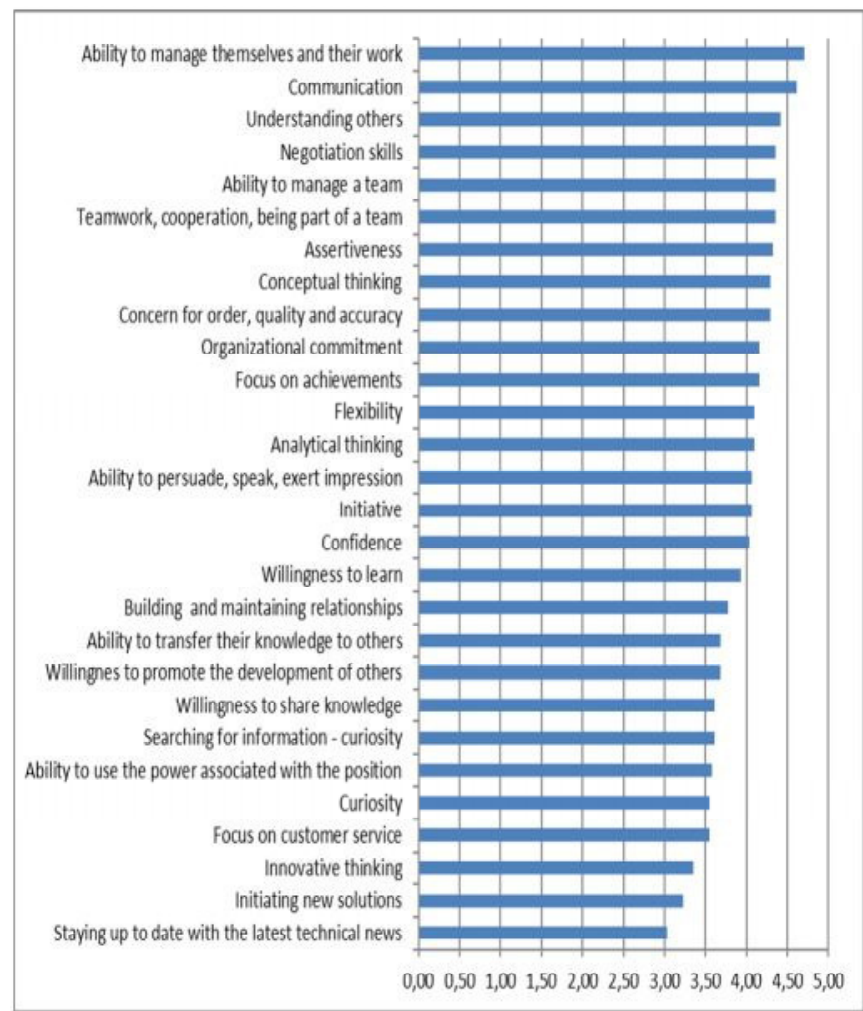

Fig. 4 Project manager competences - software developers' viewpoint

According to Q2 respondents, very important competencies of a project manager include team management skills, teamwork, cooperation, and behaving as a member of a team. However, they are not considered necessary for a technical leader. Both Q1 and Q2 respondents indicated the following competences as important: assertiveness, self-confidence, ability to build relationships, and flexibility. The last attribute in Q1 was openness to change. Other competences of a technical leader (Q1) cover courage in decision-making, perseverance, patience in the pursuit of goals, and calmness.

A technical leader who plans to be a project manager should also develop his soft skills such as conceptual and analytical thinking, organizational commitment, concern for order, quality and accuracy, the ability to speak to a group, persuasion and influence, and others. The soft competencies that are common to both lists mean that the role of a technical leader gives an employee a very good chance of becoming a Project Manager at a later stage. At the same time, we should be aware that a project manager needs more competencies and not only knowledge of project management, but also a strong commitment to personal development.

\section{DATABASE COMPETENCIES OF A TECHNICAL LEADER}

Outsourced teams may specialize in one or more areas of software engineering or technology. Almost every IT project deals with challenging problems in order to achieve scalability, security and integrity of data, and optimize database solutions.

Depending on such challenges, the competences of technical leaders may differ. As an example, technical leadership is discussed with relation to database competences. In building an optimal database solution, it is not sufficient to concentrate only on technology. There are many examples of disastrous failures of IT systems which occeured due to not only a lack of technological competence, but also to a lack of awareness of the environment in which the solution will be deployed. To overcome these problems in the future, a database practicum was introduced [22] as part of studies of database solutions at Regis University (Colorado, USA). The practicum fosters the development of soft skills by allowing students to volunteer in leadership roles, such as a Project Manager, a Technical Lead, and a Project Lead.

When considering technical leadership and database expertise, we can distinguish two approaches: the first concerns a technical leader specialized in databases, big data solutions etc., while the second is related to a general technical leader, who should have sufficient knowledge on databases. In order to determine the required competences of a technical leader specialized in databases, 100 job offers on indeed.com published in the US were analyzed.

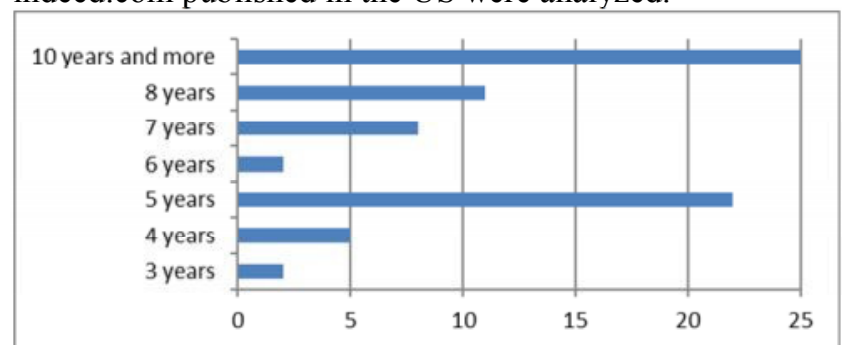

Fig. 5 Required experience of Database Technical Lead according to job offers

Most companies typically look for technical database leaders with five or ten years of experience (Fig. 5). Jobs offers for the position of a Database Technical Lead were analyzed and the required technical skills are considered below.

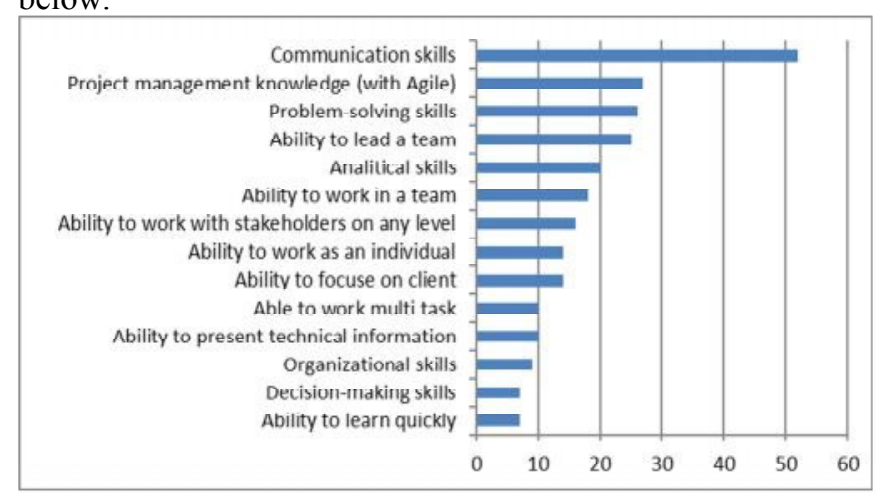

Fig. 6 Required non-domain skills of Database Technical Lead according to job offers

Supplementary to these requirements are skills and knowledge related to project management and experience as a technical leader. Job offers for the position of a Database 
Technical Lead require many non-domain competencies of leaders (Fig 6). The most common among them are communication skills (53), project management knowledge including agile approach (27), problem-solving skills (26), and ability to lead a team (25).

\section{CONCLUSIONS}

The quality of IT systems depends on the production process and the competence of the staff involved. Agile teams are now very popular. The quality of delivered software depends on technical experts who support development teams. For a Scrum team, it is important to have well prepared technical leadership that is represented by a technical leader. This paper shows that the technical lead role is well established in Scrum teams.

The role of a technical leader is not sufficiently described in the literature. In this paper, selected important characteristics of technical leaders and their career paths are described. The role's relation to project managers is clarified. It is shown that, when applying the best database solution, concentrating only on technology is not sufficient: the soft skills needed for cooperation with customers and the project team are also essential.

The study presented here is a pilot study and requires further in-depth analysis. Future studies investigating the role of a technical leader in Scrum teams should focus on the phenomenon of sustainable development. Technical leaders are required to continually develop and acquire new technical skills. Sustainable development should concentrate more precisely on different fields and the extent to which current needs are met. It is believed that acquiring knowledge and skills beyond the current demand is equivalent to wasting resources. In the rapidly changing IT sector, no one can guarantee that the knowledge gained today will be useful tomorrow. Sustainable development can also be applied in the area of soft skills development. The non-domain skills considered in the paper are a set of skills that may be useful to a technical leader, although not all of them will be used to the same extent. Further studies are needed to determine suitability of these competences, and thus to indicate the direction of the development of technical leaders.

\section{REFERENCES}

[1] R. Hoda, J. Noble, and S. Marshall, "Self-Organizing Roles on Agile Software Development Teams," IEEE Trans. Softw. Eng., vol. 39, no. 3, pp. 422-444, Mar. 2013.

[2] Tholons, "2015 Top 100 Outsourcing Destinations." www.THOLONS.com, 2015.

[3] L. D. Sienkiewicz and L. A. Maciaszek, "Adapting scrum for third party services and network organizations," in 2011 Federated Conference on Computer Science and Information Systems (FedCSIS), 2011, pp. 329-336.
[4] E. Hossain, P. L. Bannerman, and R. Jeffery, "Towards an Understanding of Tailoring Scrum in Global Software Development: A Multi-case Study," in Proceedings of the 2011 International Conference on Software and Systems Process, New York, NY, USA, 2011, pp. 110-119.

[5] S. A. Kumar and A. K. Thangavelu, "Factors affecting the outcome of Global Software Development projects: An empirical study," in 2013 International Conference on Computer Communication and Informatics (ICCCI), 2013, pp. $1-10$.

[6] D. Jayathilake, H. Yaggahavita, U. Senanayake, C. Elvitigala, and D. Sriyananda, "A scalable product quality verifier framework for a outsourcing supplier," in 2011 IEEE International Conference on Computer Applications and Industrial Electronics (ICCAIE), 2011, pp. 390-395.

[7] J. Taylor, A. Sahym, and J. Vithayathil, "Do Powerful Technology Leaders Make a Difference in Firm Performance?," 2015, pp. 4502-4512.

[8] The Open Group, TOGAF Version 9.1, 10th New edition edition. Zaltbommel: van Haren Publishing, 2011.

[9] PMI, A Guide to the Project Management Body of Knowledge: $P M B O K(R)$ Guide, 5 edition. Newtown Square, Pennsylvania: Project Management Institute, 2013.

[10] K. Jamróz, D. Pitulej, and J. Werewka, "Adapting Enterprise Architecture at a Software Development Company and the Resultant Benefits," in Software Architecture, vol. 8627, P. Avgeriou and U. Zdun, Eds. Cham: Springer International Publishing, 2014, pp. 170185.

[11] J. P. De Jong and D. N. Den Hartog, "How leaders influence employees' innovative behaviour," Eur. J. Innov. Manag., vol. 10, no. 1, pp. 41-64, 2007.

[12] J. R. Katzenbach and D. K. Smith, The Wisdom of Teams: Creating the High-Performance Organization, Reprint edition. Harvard Business Review Press, 2015.

[13] D. Clutterbuck, Coaching the Team at Work. London; Boston: Nicholas Brealey International, 2007.

[14] M. Armstrong, Managing People: A Practical Guide for Line Managers. Kogan Page Publishers, 1998.

[15] R. Friesel, "Defining the Scrum Tech Lead," Tech.Dealer.com, 23-Jul-2015. .

[16] Lemi Orhan Ergin, "Do we need Technical Leads in Scrum?," Flying to Moon, 12-Jun-2011.

[17] K. Schwaber and K. Sutherland, Scrum Guide. 2016.

[18] M. Sieraczkiewicz, Technical leadership. Gliwice: Helion, 2016.

[19] IEEE Computer Society, "Software Engineering Competency Model Version 1.0 SWECOM." IEEE Computer Society, 2014.

[20] J. Werewka and M. Wietecha, "Impact analysis of soft skills in transition from software developer to project manager positions," Bus. Inform., vol. 38, no. 4, pp. 64-90, 2015.

[21] N. Schmidt and C. Meures, "'Mind the Gap': An Analysis of Communication in Agile Global Outsourced Software Development Projects," in 2016 49th Hawaii International Conference on System Sciences (HICSS), 2016, pp. 501510.

[22] R. T. Mason, "Database Practicum for Teaching Database Administration and Software Development at Regis University," J. Inf. Technol. Educ. Innov. Pract., vol. 12, 2013. 